\title{
Autoironia e crise em "Bestiário para fagote e esôfago", poema de Augusto de Campos
}

\author{
Self-mockery and crisis in "Bestiário para fagote e esôfago", \\ a poem by Augusto de Campos
}

\author{
Adilson Antônio Barbosa Júnior \\ Universidade Federal de Minas Gerais, Belo Horizonte, Minas Gerais, Brasil
}

\begin{abstract}
Resumo: Este artigo propõe uma reflexão sobre o tópico da crise como elemento constitutivo da poesia moderna. Embora a problematização das condições desfavoráveis à poesia remonte a tempos anteriores, na modernidade essa questão torna-se um fundamento do próprio fazer poético. Nossa reflexão dá-se por intermédio da análise de "Bestiário para fagote e esôfago", poema de Augusto de Campos. O intuito é verificar de que modo a crise da poesia é veiculada no poema abordado e observar, nessa veiculação, a recorrência do emprego da autocrítica e da autoironia. Destaca-se, ainda, como a poesia moderna faz do posicionamento autocrítico uma estratégia de autoafirmação. Desse modo, além de se contemplar um proeminente poeta brasileiro, uma questão crucial acerca da poesia moderna é abordada.
\end{abstract}

Palavras-chave: Poesia; Modernidade; Crise; Augusto de Campos

\begin{abstract}
This paper proposes a reflection about crisis as a forming element on modern poetry. Despite this adverse scenario towards poetry being a known issue for many centuries, with modern poetry it becomes itself the basis for writing poems. We accomplish the discussion through the analysis of a poem by Augusto de Campos: "Bestiário para fagote e esôfago". The intent is to verify in which ways poetry crisis is dealt with in that poem and to take notice of the recurrence of self-criticism and self-mockery as well. How modern poetry makes use of this self-criticism as a strategy for selfassertion is also highlighted. Thus, besides contemplating a prominent Brazilian poet, a crucial issue about modern poetry is taken into account.
\end{abstract}

Keywords: Poetry; Modernity; Crisis; Augusto de Campos

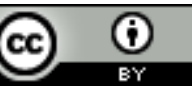


Em 1951, Carlos Drummond de Andrade publicou Claro enigma. No quarto poema desse livro, intitulado "Legado", lê-se:

\author{
Que lembrança darei ao país que me deu \\ tudo que lembro e sei, tudo quanto senti? \\ Na noite do sem-fim, breve o tempo esqueceu \\ minha incerta medalha, e a meu nome se ri. \\ E mereço esperar mais do que os outros, eu? \\ Tu não me enganas, mundo, e não te engano a ti. \\ Esses monstros atuais, não os cativa Orfeu, \\ a vagar, taciturno, entre o talvez e o se. \\ Não deixarei de mim nenhum canto radioso, \\ uma voz matinal palpitando na bruma \\ e que arranque de alguém seu mais secreto espinho. \\ De tudo quanto foi meu passo caprichoso \\ na vida, restará, pois o resto se esfuma, \\ uma pedra que havia em meio do caminho. (ANDRADE, 1991, p. 19)
}

O emprego da forma fixa do soneto, do tom solene, bem como dos versos alexandrinos, rendeu críticas a Drummond. Haroldo de Campos, por exemplo, diagnosticou aí uma tentativa de tributo e incorporação à tradição (CAMPOS, H., 1992, p. 52). No entanto, é possível defender que o efeito mais pungente de "Legado" seja exatamente o oposto. Embora a forma e a dicção do poema possam gerar a expectativa de uma afirmação dos valores clássicos da poesia, essa expectativa se frustra, pois dos versos resultam, na verdade, o ceticismo e o desencanto. O poema remata por contradizer o preceito horaciano de perenidade da poesia: "Não creias que hão de perecer as palavras que eu, nascido junto ao Áufido que ressoa ao longe, pronuncio, por artes não antes conhecidas, para as associar às cordas" (HORACIO apud ACHCAR, 1994, p. 177). Francisco Achcar aponta, em "Legado", a presença de "ironia estilística” (ACHCAR, 1994, p. 176). O estilo que parece, à primeira vista, aliar-se ao ideal clássico da permanência é, desse modo, o viés irônico de constatação da impossibilidade desse mesmo ideal naquele presente: o dos "monstros atuais", isto é, o dos tempos modernos.

Em "Legado", a condição de poeta não importa num contexto no qual não se consolidou uma tradição de sabedoria. A lira não seduz o mundo; o mundo se fecha ao poeta, que está calado - "taciturno" -, sem esperança de integração plena, desnorteado “entre o talvez e o se". O sujeito poético desvia-se também da premissa horaciana de utilidade e deleite (prodesse et delectare): sua voz não soará em "canto radioso", nem como bálsamo que "arranque de alguém seu mais secreto espinho". Não é o caso de ler aqui uma expressão de humildade ou nostalgia. O ceticismo se imprime no poema por 
meio do que Luiz Costa Lima denomina, na poética de Drummond, "princípio-corrosão": "escavação" ou "cega destinação para um fim ignorado" (LIMA, 1995, p. 131, grifos do autor). Conforme o teórico, na fase drummondiana em que se situa Claro enigma a corrosão é um "ponto de partida" que se confunde "com o seu resultado: vazio". (LIMA, 1995, p. 175). Retomando o tema em ensaio posterior, Costa Lima complementa:

O mundo é anterior a princípios humanos; fechado e vazio. O arabesco que o declara não é mais fruto da tentativa de conjugar numa forma o múltiplo e o disperso; de articular o acidente e o significativo; é ornamento do nada. (LIMA, 1989, p. 303)

Não há, portanto, assunção de uma empreitada órfica - conjugação do múltiplo e do disperso. Orfeu vaga "taciturno", silente. O canto se dissolve no ar, no vento ("é ornamento do nada", como acima transcrito), e não permanecerá: "pois o resto se esfuma" - o que é paradoxalmente tematizado com emprego da forma fixa do soneto. No mito de Orfeu, a cabeça e a lira do herói esquartejado vão dar à ilha de Lesbos, legando a poesia à humanidade. Na antiode horaciana de Drummond, o sujeito poético ironiza corrosivamente o desencanto do mundo em que traça seu périplo vão - "meu passo caprichoso" -, do qual remanescerá tão somente o opaco obstáculo: "uma pedra que havia em meio do caminho", em uma referência ao poema, do próprio autor, "No meio do caminho tinha uma pedra".

Se o poema de Drummond contradiz irônica e corrosivamente o tópico da perenidade, inerente à poética clássica, por outro lado ele traz em seu bojo um tópico central da poética moderna: o da crise da poesia, ou, em outros termos, o topos do questionamento da própria possibilidade da poesia na modernidade.

Embora seja necessário concordar com Michael Hamburger quando este afirma, opondo-se a Hugo Friedrich, que "não há uma coisa como um único movimento moderno na poesia, inteiramente internacional e progredindo em linha reta desde Baudelaire até a metade deste século [século XX]" (HAMBURGER, 2007, p. 43), pode-se dizer que é possível, sim, identificar a recorrência de determinados topoi na poesia desse intervalo a poesia dita moderna. É o caso, por exemplo, do tópico da crise da poesia. Como afirma Costa Lima, a comunidade de expectativas entre poeta e leitor "progressivamente decresce desde a publicação de Les fleurs du mal" (LIMA, 2012, p. 203). E o sentimento de crise foi reiterado, por diferentes vias, em obras de poetas posteriores a Baudelaire. No 
livro Poesia e crise, Marcos Siscar reitera, em vários dos ensaios ali reunidos, que a noção de crise é constitutiva da própria poesia moderna. O topos da distância entre sociedade e poesia, ainda que remonte a tempos anteriores - o autor cita um exemplo em Camões -, retorna na modernidade de modo mais intenso, como fundamento da própria atividade poética:

\footnotetext{
O tema do mal-estar, do presente como época de desolação, da falta de condições de poesia, da falta de poesia ou da poesia que falta, em suma, é mais (ou menos) do que uma informação ou uma constatação sociocultural: ele parece constituir o modo pelo qual a poesia apresenta modernamente seu "programa", seu sentido dentro do conjunto de vozes sociais. (SISCAR, 2010c, p. 42 , grifo do autor).
}

No caso do poema "Legado", de Drummond, ocorre a assimilação da pedra, que, igualmente obstáculo, é ali um emblema da permanência possível da poesia em um dado “conjunto de vozes sociais". Já o poema "No meio do caminho tinha uma pedra" configura um marco do modernismo brasileiro e não deixa de simbolizar, especialmente na maneira como é referenciado em "Legado", o gesto de incorporação da crise à poesia moderna. No presente artigo, pretendemos analisar "Bestiário para fagote e esôfago", de Augusto de Campos, com o intuito de apontar como a noção de crise da poesia é engendrada nesse poema e, ainda, como o reiterado emprego da autocrítica e da autoironia termina por conformar também uma postura de resistência e autoafirmação da poesia que se reconhece em crise.

"Bestiário para fagote e esôfago" foi composto em 1955 - conforme indicação do autor - e publicado em 1962, quando integrou, na condição de inédito, a antologia Noigandres 5: do verso à poesia concreta. Trata-se do período combativo do movimento concretista: é em 1955 que Augusto de Campos utiliza pela primeira vez a expressão "poesia concreta" (CAMPOS, A., 1955, p. 55) e o "Plano-piloto para poesia concreta" sai na Noigandres 4, de 1958. Posteriormente "Bestiário para fagote e esôfago" passou a integrar a reunião poética intitulada Viva vaia: poesia 1949-1979 (CAMPOS, A.,1979, p. 79-89), a partir da qual o citamos ao longo de todo este artigo.

O poema é dividido em sete partes, sendo que cada um desses segmentos ocupa parcialmente uma página. Parcialmente, no entanto, do ponto de vista tipográfico, já que o espaço em branco também desempenha ali uma função estrutural. O título "Bestiário para fagote e esôfago", como se percebe claramente, é inspirado na linguagem musical. 
Aliás, o paralelo com a música é frequente na obra de Augusto. Por exemplo, no pórtico de Poetamenos, livro publicado em 1953, vem a declaração explícita do intento de se aproximar, em poesia, da "melodia de timbres" de Anton Webern (CAMPOS, A., 1979, p. 65). O termo "bestiário" deve-se à série de animais a que, ao longo do poema, a figura do poeta é comparada. Já "fagote" e "esôfago" possibilitam ao menos duas leituras. A primeira, motivada pela repetição do morfema "fago", suscita, em sentido geral, as noções de ingestão e digestão; e, em sentido específico, remete à antropofagia oswaldiana, que aparece também no corpo do poema, como veremos. Uma segunda leitura, que não exclui a primeira, é a de uma aproximação da imagem do texto na página com a imagem de um fagote, instrumento de sopro alongado que o executante posiciona verticalmente defronte ao próprio corpo, em linha paralela ao esôfago. Os sete fragmentos de "Bestiário para fagote e esôfago" são dispostos no centro da página, numa figuração bastante estreita. O tipo gráfico utilizado, por ser delgado, acentua essa característica. Visualmente, as manchas tipográficas são como feixes afilados, similares ao fagote. Aliás, uma possível origem do termo "fagote" é o francês fagot, que significa feixe de lenha (SADIE, 1994, p. 309). Essa apresentação angustiante, estreita, materializa - de modo similar a um ideograma - a concisão com que Augusto norteou praticamente toda a sua obra, e que, já anteriormente a "Bestiário para fagote e esôfago", vinha plasmada nos títulos do livro Poetamenos (1953) e do poema "Ad Augustum per angusta", publicado em 1952, na Noigandres 1 .

A referência à linguagem musical, presente no título "Bestiário para fagote e esôfago", nos leva a considerar também a importância da oralização no caso desse poema. A oralização como objetivo da poética de Augusto aparece no já mencionado pórtico de Poetamenos: "reverberação: leitura oral". (CAMPOS, A., 1979, p. 65, grifo do autor). Em 1954 Décio Pignatari chegou a organizar uma leitura pública, a várias vozes, de Poetamenos, numa reação contra críticas que argumentavam a impossibilidade de oralização dos poemas desse livro. Além disso, na denominação do projeto do movimento, a partir do termo cunhado por James Joyce, aparece o elemento vocal: "verbivocovisual" (CAMPOS, A. et al., 2006, p. 216). Mas, por outro lado, a própria constituição de "Bestiário para fagote e esôfago" leva a essa oralização. Analisando um poema posterior - intitulado "ão" -, mas de estrutura muito similar à de "Bestiário para fagote e esôfago", Flora Süssekind fala em "sonoridade e vocalização implícitas", 
estimuladas pela "trama sublexical, silábica, fonêmica" do poema. Também o poema em análise apresenta essa compleição fragmentária, que induz à reconstituição fônica do que foi "desconstruído graficamente" (SÜSSEKIND, 2004, p. 153). Especificamente quanto a "Bestiário para fagote e esôfago", Süssekind chama a atenção para a afinidade desse poema com a experimentação de e. e. cummings, poeta importante para Augusto e para o movimento concretista. Ao escrever sobre cummings, Augusto destaca justamente a junção entre o visual e o vocal, e intitula o texto de apresentação das traduções que fez do poeta norte-americano "e. e. cummings: olho e fôlego" (CAMPOS, A., 1986, p. 15).

O primeiro dos sete fragmentos, embora se inicie com um vocábulo afirmativo "sim" -, traz uma significativa carga de negatividade. O poeta é dito "infinitesimal" e existe apenas "em tese". A quebra da palavra "infinitesimal" possibilita também que se leia a sequência "mal / (em tese) / existe". Assim, grifa-se a condição negativa da existência do poeta: que mal existe e é "infinitesimal". Insinua-se, desde esse início, a ironia - e sobretudo a autoironia - que se acentua nos segmentos subsequentes. Nesse segmento já se percebe também a referência a cummings pela atomização dos vocábulos e pelo uso da tmese. $\mathrm{O}$ autor realiza uma tmese a partir do próprio nome desse recurso gramatical em paronomásia com a expressão "em tese": "sim / o poeta / infin / itesi / (tmese) / mal / (em tese) / existe". Na sequência, a ação do poeta é apresentada como sendo de resistência, pois ele se manifesta "ainda": "e se mani / (ainda) / festa". Aqui há de se observar que a manifestação do poeta é também "festa" - resultante da atomização de "manifesta". A concepção de poesia como festa remonta aos trovadores provençais alguns traduzidos por Augusto -, cuja ideia de alegria, joi, era muitas vezes tida como o objetivo do fazer poético. Um exemplo bem nítido é o emblemático poema de Arnaut Daniel do qual os concretistas extraíram o nome do grupo, Noigandres: "Então todo o meu ser quer que eu colora o canto / De uma flor cujo fruto é só de amor / O grão só de alegria e o olor de noigandres" (DANIEL apud CAMPOS, A., 1988, p. 53).

Tornando ao poema em análise, observamos que a manifestação do poeta é situada: "nesta / ani / (triste) / mal / espécie / que lhe é / funesta". A rima entre "festa", "nesta" e "funesta" (a espécie) não deixa de conter também certa ironia. De resto, em todo o poema o uso da rima é bem distante do convencional. A espécie, no caso, é a humana. E o dêitico "nesta" indica tratar-se da espécie do próprio poeta, ou seja, é na espécie humana que o poeta se "manifesta", apesar de essa espécie lhe ser "funesta" - lhe causar 
ou pressagiar a morte. Além de "funesta", a espécie humana também é descrita como "ani / (triste) / mal". "Triste" está em oposição a "festa", que é associada à poesia. Mas, a qualidade de "triste" tanto é atribuída à humanidade quanto ao poeta, já que ele também se situa "nesta" espécie. Nesse mesmo sentido, é preciso observar que "triste" está posicionado em tmese com a palavra "animal": "ani / (triste) / mal". Da forma como o poema estrutura esses termos, a imagem que resulta é a de que "triste" está dentro de "animal", que, por sua vez, remete a "alma" - anima - e a "ânimo", "animado". A tristeza estaria, então, no âmago - na alma - dessa espécie, que é também a do poeta, e na qual ele "ainda festa". Em razão da fragmentação das palavras, "festa", além de compor o termo "manifesta", funciona isoladamente como forma verbal, a significar "festeja".

Os segmentos posteriores contêm uma série de comparações do poeta a animais. Gonzalo Aguilar fala em "transformações" ou "metamorfoses" (AGUILAR, 2005, p. 284-285). A transmutação do poeta em animais funcionaria, assim, como estratégia de sobrevivência. Não descartamos a noção de estratégia, mas entendemos que, na verdade, o poeta é comparado aos animais. Desse modo, as comparações denotam a ampla gama de esforços - ou estratégias - que o poeta empreende para que a poesia continue possível - se manifeste "ainda", conforme a linguagem do poema - apesar da situação de crise, "funesta".

Assim, no segundo trecho do poema, o poeta, "ao / ver-se / perse / guido / bufa". A forma verbal "bufa" denota a fadiga gerada pela perseguição e, no movimento de idas e vindas que a atomização dos vocábulos propicia em todo o poema, é possível ler, com a partícula "lo" que a linha seguinte acrescenta: o poeta búfalo se esconde. A imagem é ambivalente, pois o poema fala em perseguição e na ação de esconder-se, mas, por outro lado, o búfalo é um animal que sugere a ideia de força, de resistência. Por isso, percebemos um teor de negatividade - o poeta é perseguido -, mas também de autoafirmação - o poeta é como um búfalo, que resiste. Logo em seguida tem-se: "flor de / estufa / sua / língu / a conde / corada / a extingu / ir-se". A qualificação da língua poética como "flor de estufa" traz a noção de linguagem fabricada, isto é, resultante do fazer (poiésis). A fragmentação dos vocábulos permite uma dupla adjetivação da palavra "língua", que tanto é "corada" como "condecorada". Essa última acepção pode ser lida como menção a uma dignidade perdida, que a poesia - língua dos poetas - possuíra anteriormente, ou seja: a condecoração reflete uma distinção que, como se depreende do 
que o poema diz, não se manteve. A ideia de perda da dignidade, somada à conclusão desse segmento - "a extingu / ir-se" - configuram o que Siscar chama de "retórica apocalíptica" (SISCAR, 2010a, p. 10, grifo do autor), um dos meios pelos quais se materializa a crise constitutiva da poesia moderna. Porém, é preciso destacar a dupla leitura que a fragmentação dos vocábulos novamente possibilita. Em “extingu / ir-se" lêse "extinguir-se", mas, na linha final, isolada, lê-se: "ir-se", expressão que remete a prosseguimento. Desse modo, a linguagem poética está simultaneamente em extinção e em continuidade.

O terceiro segmento continua a sequência de associações do poeta a animais ou a motivos animais. O poeta é taxado de "parasita paralítico". Vemos aqui uma alusão ao preconceito - comum numa civilização que evoluiu para uma sociedade de consumo, regida pela lógica da produção material - que vê no poeta um parasita social, já que a poesia não é valorizada, muito menos materialmente. Paula Glenadel lembra a associação do poeta à figura da cigarra - outra metáfora animal - presente na conhecida fábula de La Fontaine sobre a cigarra e a formiga e também no Fedro, de Platão. Em ambos os casos, a cigarra - isto é, o poeta - é o extremo oposto do pragmático e da organização material (GLENADEL, 2011, p. 142-147). Essa qualificação reles do poeta como "parasita paralítico" é, logo após, utilizada para a desmistificação da figura do poeta condoreiro, ícone da poesia de índole subjetiva no romantismo. O voo do condor, ao planar, é de certa forma passivo, como a inércia do parasita. A noção de uma escrita poética por inspiração, afim aos ideais românticos, também se coaduna com a passividade sugerida. Assim, o poeta, "parasita paralítico", "se equipara" ao "condor no voo à brisa". No entanto, esse segmento também se constrói de modo ambivalente. Há uma tensão dessas imagens iniciais com as que se seguem. Se o voo do condor é primeiramente desmistificado, é logo em seguida equiparado “à / seca / lista / de zebra / em / zoo". Essa referência à camuflagem, recurso de proteção natural da zebra, também se inscreve no rol de metáforas que endossam a engenhosidade do poeta. $\mathrm{O}$ emprego da tmese multiplica as possibilidades de composição entre os fragmentos atomizados. Assim, por exemplo, é possível ler "equi" mais "para" ou "equi" mais "libr" mais "ista". De acordo com essa última chave de leitura, o poeta é um "equilibrista" - é habilidoso, portanto. Vale observar, por fim, que nesse terceiro segmento as palavras ou sílabas são dispostas de modo propositalmente desalinhado, o que gera a visualidade de uma oscilação. Desse 
modo, o filamento todo, no centro da página, isomorfiza três imagens das quais trata: o voo do condor, a lista curvilínea da zebra e a performance do equilibrista.

O sintético quarto segmento diz: "se / tem / fome / come / fama / como / cama / leão / come / ar". Aqui é fundamental observar que a repetição da bilabial [m] gera uma mímica por parte do leitor que, ao vocalizar o poema, reproduz o movimento do camaleão inflando e desinflando o papo ("comendo" ar) ou simplesmente o movimento de mastigar: "fome / come / fama / como / cama" (grifos nossos). Esse segmento ironiza a noção de reconhecimento público, já que ter "fama" como poeta não gera retorno material - daí a equiparação da "fama" ao "ar", ambos ineficazes como alimento. Por outro lado, novamente o poema frisa, metaforicamente, uma capacidade do poeta: alimentar-se de ar. Vemos aí uma referência à expressão popular "viver de brisa". A referência acentua a ironia dirigida à "fama”, que não garante ao poeta condições de sobrevivência.

Com o cuidado de afastar qualquer identificação entre a figura do poeta veiculada pelo poema e o autor empírico, destacamos uma afirmação de Augusto sobre poesia e valor material: "Num quadro de injusta distribuição social, como o nosso, em que o lucro e o mercado são os motores da vida, os poetas são os sem-terra culturais. Pode um poeta viver de sua poesia?" (CAMPOS, A., 2004, p. 17).

O próximo segmento - o quinto - retoma a referência à antropofagia de Oswald, já anunciada no título do poema pela repetição do morfema "fago" nos termos "fagote" e "esôfago": "al / moço / antes / doce / do / intes / tino / fino / ao / gr / osso". Lemos aqui a atitude crítica do poeta que, por assim dizer, "digere" a tradição anterior - no poema: “antes”. Dessa tradição, uma parte é descartada - como o intestino descarta o que o organismo não deve aproveitar - e a outra passa a constituir também o poeta que a absorve: "osso". Não é gratuita a menção ao intestino, já que este é justamente o órgão de seleção do aparelho digestivo - o órgão crítico, portanto, em consonância com a etimologia do verbo criticar, do grego krineïn (separar). A argúcia do poeta crítico é expressa em "tino / fino". Já o termo "doce" sugere a poesia romântico-sentimental. A forma delgada do filamento, com as palavras isoladas ou mesmo fragmentadas, faz com que a leitura desse quinto segmento se dê verticalmente, metaforizando o movimento do bolo alimentar que passa pelo esôfago e vai até o intestino.

Apesar de Augusto ser um poeta assumidamente de vanguarda, sobretudo no momento em que produz o poema ora estudado, não é de se estranhar que a relação com 
a tradição seja aqui valorizada. Costa Lima destaca que o combate do Concretismo "não era à poesia do passado enquanto passado, mas sim à composição da rotina" (LIMA, 2004, p. 117). Os idealizadores do Concretismo propunham não simplesmente uma ruptura total com a tradição, mas sim uma reorganização da tradição, com o descarte da parcela do cânone que julgavam equivocada e também com o resgate de obras e autores que consideravam injustamente renegados. Daí terem adotado a noção de paideuma, que no grego abrange as noções de "educação" e de "formação", e que Ezra Pound empregou também no sentido de uma espécie de repertório de poetas com os quais se pode aprender e cujas ideias prestam-se à renovação da tradição (Ver POUND, 1970, p. 153).

No penúltimo trecho de "Bestiário para fagote e esôfago" acentua-se o retrato do desprestígio social da poesia: "mais / baixo / que / o / lixeiro / que / cheira / a / lixo / mas / ao / menos / tem / cheiro / o / poeta / lagartixa / no / escuro / bicho / inodoro". O substantivo "lagartixa" é convertido em forma verbal para gerar o sentido de um arrastarse bem próximo ao chão, como faz o réptil. Há a conotação depreciativa, de algo que é reles. No entanto, é plausível também o sentido de "esgueirar-se", isto é, locomover-se em espaços estreitos, angustiantes - e, ainda, "no escuro". Desse modo, é traçada a visão social acerca do poeta, mas também é afirmada a capacidade de adaptação que ele detém - como uma lagartixa que mimetiza as cores do ambiente para tornar-se imperceptível e, assim, se proteger. O poeta não desperta a atenção da sociedade - atenção que, no poema, é metaforizada pelo sentido do olfato -, pois é "inodoro", não tem nenhum cheiro: nem bom, como seria desejável, nem mau, como o do lixo. A reação diante da poesia e do poeta é, portanto, de indiferença. Além de inodoro, o poeta também é "solitário / em / seu / labor / atório / sem / sol / ou / sal / ário". Aqui se expressa o isolamento que advém do fazer poético: "labor" em um local inóspito, "sem sol". Como o albatroz de Baudelaire, o poeta está “exilado no chão" (BAUDELAIRE, 1985, p. 111).

O emprego da palavra "laboratório" não pode ser menosprezado. O termo remete diretamente à ideia de experimentação, fundamental na poética de Augusto. Também reclama atenção o fato de o poema caracterizar a atividade poética como um labor sem "salário". Como pontuamos ao comentar o terceiro e quarto segmentos do poema, poesia e valor material parecem refratários. No ensaio $O$ preço da poesia, Glenadel, ao comentar um poema de Fabiano Calixto, assinala que 
a poesia custa muito mais do que aporta, pelo menos segundo a visão habitual. Mas ela teria a vantagem de constituir-se na direção de uma economia do desacerto, capaz, por isso, de indagar sobre o valor do valor. (GLENADEL, 2011, p. 41).

A conclusão de Glenadel refere-se, como dissemos, ao texto de Calixto. Mas parece adequar-se ao poema ora comentado. O poeta aludido em "Bestiário para fagote e esôfago" destina-se, por via do fazer poético - o "labor" - ao status rebaixado, à indiferença alheia e ao isolamento; esse é o "custo" da poesia. Por outro lado, tal labor não gera retorno: é "sem sol ou salário". Ainda assim, esse descompasso de valores - "o valor do valor", na expressão de Glenadel - é questionado pela ironia que perpassa todo o poema. A sociedade que relega o poeta e a poesia a essa "economia do desacerto" (GLENADEL, 2011, p. 41) é também criticada em razão dos valores que cultiva.

O sétimo e último segmento retoma os anteriores para resumi-los na expressão "cate / goria / oficial / do / vate". A situação precária do poeta - o "vate" -, exposta no poema, é sua "categoria". Mas ironicamente, essa é a categoria "oficial”. Fica implícito, portanto, que há uma categorização extraoficial para o poeta. E esta será possivelmente oposta ou resistente à "oficial". Desse modo, pode-se dizer que o movimento de negativas do poema sustenta - pelo sentido inverso - uma ideia de afirmação e de resistência da poesia perante o contexto de crise. E esse viés afirmativo deixa-se perceber sobretudo pela dicção irônica. Comentando um poema de Augusto intitulado "desplacebo" (1997), Costa Lima aduz: "Para que o não seja sim, precisa antes afirmar-se como negativa pura, dar as costas ao território onde se propaga o fácil - valor primeiro da sociedade de consumo" (LIMA, 2004, p. 121, grifos do autor). ${ }^{1}$ Desse modo, se a sociedade não prestigia o poeta - não lhe atribui valor e à poesia -, este tampouco se entrega, ainda que essa negativa lhe renda a desventura de uma malfadada "categoria oficial".

No fecho do poema é dito que ao poeta, "o vate", "como é justo / se esbate / assim que se mate - / o / augusto / busto". Com ácida ironia, a conclusão é a de que, quando o poeta morre, a sociedade lhe faz uma pretensa justiça - "como é justo" - através da escultura de um busto. Ironicamente, pode tratar-se tanto de um suicídio quanto de um assassínio, já que em "assim que se mate" o sujeito tanto pode ser reflexivo quanto indeterminado. A ironia salienta também outra face da questão, a da apropriação inócua

\footnotetext{
${ }^{1}$ Não se pode esquecer, todavia, que a publicidade, motor fundamental da sociedade de consumo, terminou por apropriar-se de muitos dos recursos inerentes à poesia concreta.
}

Revista da Anpoll, Florianópolis, v. 52, n. 3, p. 40-54, set.-dez., 2021 | 50 
e vazia da imagem do poeta, isto é: a obra não é valorizada em vida do autor, mas a morte gera a apropriação da figura do poeta como suposto "bem cultural", precariamente materializado em um busto de pedra. Com isso o poema questiona também a noção de cânone, à qual é intrínseca a de monumentalização. É igualmente relevante a autoironia através do emprego do próprio nome do autor, "augusto". Aguilar lembra que "augusto" significa "sagrado" (AGUILAR, 2005, p. 286). Todavia, o que se observa é a dessacralização da figura do poeta, e a morte pressagiada no segmento inicial - o poeta em meio à "espécie que lhe é funesta" - realiza-se no final do poema.

A crise se insere, portanto, em "Bestiário para fagote e esôfago", principalmente pela reiteração da atitude hostil, por parte da sociedade, direcionada ao poeta. Siscar, ao comentar os modos de realização, na poesia moderna, do discurso da crise, fala em um "dispositivo sacrificial":

Consiste em entregar a própria cabeça, em reconhecer-se como vítima, transformar-se em vítima e, assim, em termos de constituição textual e discursiva, em fazer-se vítima (SISCAR, 2010c, p. 43, grifos do autor).

Essa vitimização pode ser observada não apenas no último segmento, em que se tematiza a morte do poeta, mas também nos segmentos anteriores, conforme vimos. A dimensão sacrificial, contudo, não visa à restituição do sagrado - que o poema remata por profanar -, mas à instituição de "um lugar distinto para a poesia: um lugar crítico, de paradoxal resistência" (SISCAR, 2010b, p. 32, grifo do autor). Ainda que esse lugar seja "infinitesimal", como qualifica o poema.

Aguilar, ao comentar "Bestiário para fagote e esôfago", embora reconheça que esse espaço infinitesimal seja "potencialmente infinito", entende que o poeta é aí “acuado" (AGUILAR, 2005, p. 286). Não nos parece, ao menos no caso da poética de Augusto, que tal situação resulte de um acuamento. A concisão do mínimo é, sim, uma diretriz voluntariamente adotada por esse poeta como resultado de uma postura autocrítica. Na poesia de Augusto a negação e o estreitamento recaem tanto sobre o sujeito quanto sobre o fazer poéticos. Como aduz Eduardo Sterzi, “[a] coerência da trajetória de Augusto não é simples, mas complexa. De seus primeiros poemas até os poemas propriamente concretos, verifica-se um progressivo esvaziamento do sujeito lírico" (STERZI, 2004, p. 105). No tocante à negação autorreflexa da poesia, a simples observação dos títulos de alguns dos livros de Augusto evidencia essa reafirmação do 
“infinitesimal”, bem como a incorporação, ao texto, da ideia de crise da poesia: Poetamenos (1953); Expoemas (1985); Despoesia (1994); Não (2003). Escrever-se "infinitesimal”, nesse caso, não é adequar-se a um acuamento, mas sim adotar antecipadamente o conselho cabralino em "A palo seco", de Quaderna (1960), que não era de "aceitar o seco / por resignadamente, / mas de empregar o seco / porque é mais contundente" (MELO NETO, 1960, p. 75). A autocrítica presente em "Bestiário para fagote e esôfago" realiza, assim, o discurso da crise. E a ironia, bem como a autoironia, convertem esse espaço angustiante - estreito - na contundência estratégica de afirmação da poesia pela tese do não.

\section{Referências}

ACHCAR, Francisco. Lírica e lugar-comum: alguns temas de Horácio e sua presença em português. São Paulo: EDUSP, 1994.

AGUILAR, Gonzalo. Poesia concreta brasileira: as vanguardas na encruzilhada modernista. São Paulo: EDUSP, 2005.

ANDRADE, Carlos Drummond de. Claro enigma. 2. ed. Rio de Janeiro: Record, 1991.

BAUDELAIRE, Charles. As flores do mal. Trad. Ivan Junqueira. 5. ed. Rio de Janeiro: Nova Fronteira, 1985.

CAMPOS, Augusto de. e. e. cummings: olho e fôlego. In: CUMMINGS, E. E. 40 poemas. Trad. Augusto de Campos. São Paulo: Brasiliense, 1986. p. 15-17.

CAMPOS, Augusto de. Verso, reverso, controverso. 2. ed. São Paulo: Perspectiva, 1988.

CAMPOS, Augusto de. Viva vaia: poesia 1949-1979. São Paulo: Duas Cidades, 1979.

CAMPOS, Augusto de. Poetamenos. In: CAMPOS, Augusto de. Viva vaia: poesia 1949-1979. São Paulo: Duas Cidades, 2001. p. 63-77.

CAMPOS, Augusto de. Entrevista a José Carlos Prioste. Poesia Sempre. Rio de Janeiro: Biblioteca Nacional, n. 19, p. 13-23, dez. 2004.

CAMPOS, Augusto de. Poesia concreta. In: CAMPOS, Augusto de; CAMPOS, Haroldo de; PIGNATARI, Décio. Teoria da poesia concreta: textos críticos e manifestos 19501960. 4. ed. Cotia: Ateliê, 2006. p. 55-65. 
CAMPOS, Augusto de; CAMPOS, Haroldo de; PIGNATARI, Décio. Plano-piloto para poesia concreta. In: CAMPOS, Augusto de; CAMPOS, Haroldo de; PIGNATARI, Décio. Teoria da poesia concreta: textos críticos e manifestos 1950-1960. 4. ed. Cotia: Ateliê, 2006. p. 215-218.

CAMPOS, Haroldo de. Drummond, mestre de coisas. In: CAMPOS, Haroldo de. Metalinguagem \& outras metas: ensaios de teoria e crítica literária.4. ed. São Paulo. Perspectiva, 1992. p. 49-55.

GLENADEL, Paula. O preço da poesia: pequena meditação em quatro tempos sobre valor e literatura. São Paulo: Lumme, 2011.

HAMBURGER, Michael. A verdade da poesia. Trad. Alípio Correia de Franca Neto. São Paulo: Cosac Naify, 2007.

LIMA, Luiz Costa. A aguarrás do tempo: estudos sobre a narrativa. Rio de Janeiro: Rocco, 1989.

LIMA, Luiz Costa. Lira e antilira: Mário, Drummond, Cabral. 2. ed. Rio de Janeiro: Topbooks, 1995.

LIMA, Luiz Costa. Duas aproximações ao não como sim. In: GUIMARÃES, Júlio Castañon; SÜSSEKIND, Flora (Orgs.). Sobre Augusto de Campos. Rio de Janeiro: Sete Letras, Fundação Casa de Rui Barbosa, 2004. p. 116-129.

LIMA, Luiz Costa. A ficção e o poema. São Paulo: Companhia das Letras, 2012.

MELO NETO, João Cabral de. Quaderna. Lisboa: Guimarães Editores, 1960.

NOIGRANDRES 5: do verso à poesia concreta. São Paulo: Massao Ohno, 1962.

POUND, Ezra. Guide to Kulchur. New York: A New Direction, 1970.

SADIE, Stanley (Org.). Dicionário Grove de música: edição concisa. Trad. Eduardo Francisco Alves. Rio de Janeiro: Jorge Zahar, 1994.

SISCAR, Marcos. Apresentação. In: SISCAR, Marcos. Poesia e crise: ensaios sobre a "crise da poesia" como topos da modernidade. Campinas: Editora da Unicamp, 2010a. p. 9-13.

SISCAR, Marcos. O Discurso da crise e a democracia por vir. In: SISCAR, Marcos. Poesia e crise: ensaios sobre a "crise da poesia" como topos da modernidade. Campinas: Editora da Unicamp, 2010b. p.17-40.

SISCAR, Marcos. "Responda, cadáver": as palavras de fogo da poesia moderna. In: SISCAR, Marcos. Poesia e crise: ensaios sobre a "crise da poesia" como topos da modernidade. Campinas: Editora da Unicamp, 2010c. p.41-54. 
STERZI, Eduardo. Todos os som, sem som. In: GUIMARÃES, Júlio Castañon; SÜSSEKIND, Flora (Orgs.). Sobre Augusto de Campos. Rio de Janeiro: Sete Letras, Fundação Casa de Rui Barbosa, 2004. p. 95-115.

SÜSSEKIND, Flora. (Quase audível): nota sobre "ão". In: GUIMARÃES, Júlio Castañon; SÜSSEKIND, Flora (Orgs.). Sobre Augusto de Campos. Rio de Janeiro: Sete Letras, Fundação Casa de Rui Barbosa, 2004. p. 140-158.

Recebido em: 20 de setembro de 2021 Aceito em: 01 de dezembro de 2021 Publicado em dezembro, 2021 